\title{
The model of the distribution of oilseed processing products to foreign markets
}

\author{
Natalya Pyzhikova ${ }^{1}$, Kristina Chepeleva ${ }^{1 *}$, and Pavel Shvalov ${ }^{1}$ \\ ${ }^{1}$ FSBEI HE Krasnoyarsk State Agrarian University, 90, Mira Avenue, Krasnoyarsk, 660049, Russian \\ Federation
}

\begin{abstract}
The article presents the results of a study of the world market of oilseeds and products of their processing, regional features of the agroindustrial complex (AIC) of the Krasnoyarsk Territory, as well as the rationale for the development of the region's export activities in this direction. The purpose of the study is the formation of the model of the distribution of oilseed processing products to foreign markets. Research methods - an analytical and research arsenal of methods and methodological techniques: logical and situational analysis, diagnostics and monitoring, tabular and graphical techniques for interpreting factual information. Among general scientific methods, analysis, synthesis, deduction and induction, analogy have found application. The results of the Research: segmentation of consumers of vegetable oils, marketing complex of products, model of distribution of products to the market of vegetable oils of China. The formed distribution model is based on the goals of the enterprises of the agro-industrial complex of the Krasnoyarsk Territory: to introduce a new product (vegetable oils: rapeseed, cameline, mustard) and expand its presence to the markets. The formed distribution model will expand the possibilities of diversifying the activities of agricultural enterprises in the region when entering the foreign markets and will serve as a serious methodological basis for the design of innovative business models.
\end{abstract}

\section{Introduction}

In the world market there is a steadily increasing demand for vegetable oils. According to the Ministry of Agriculture of the Russian Federation, the oil and fat complex from all branches of the food industry has the greatest potential for increasing exports.

Oilseeds as a separate export destination are very relevant for Russia as a whole and the Krasnoyarsk Territory in particular.

In the Krasnoyarsk Territory, agricultural commodity producers began to actively include oil crops in crop rotation. Sown areas of oilseeds in the region for the period of 2015-2019 had been increased by 4.5 times [1]. The increase in crop area in the region, as well as an increase in seed production - by 2.8 times in 2019 compared to 2015 to 185

\footnotetext{
*Corresponding author: kristychepeleva@mail.ru
} 
thousand tons [1] contributed to the expansion of export opportunities for oilseed producers and an increase in supplies to China and Mongolia.

The successful location of the region offers great opportunities for exporting oilseed products to East Asian countries.

According to export data on oilseeds, fats and oils, for the period of 2015-2019, the main countries that import oilseeds are China, Mongolia, Kazakhstan, oils and fats are supplied to Belarus, Abkhazia, Mongolia, China [2]. The total volume of Russian exports in the period since $2015-2019$ is growing annually and amounts to $\$ 1.02$ billion $(+32.8 \%)$ in oilseeds in 2019 compared with the previous year, and \$ 268 million in oils and fats, which $28.6 \%$ more than the same period [2].

Currently, the region exports one of the oilseeds - rapeseed to foreign markets, in 2019 the supply of oilseeds was $\$ 0.01$ billion $(+106.2 \%$ by 2018 [2]). The chosen path of the region is raw, which does not allow to get the maximum economic return on rapeseed and is too dependent on external conditions. The region is capable of producing not only traditionally safe, but also modern, high-quality products of a wide assortment (rapeseed, cameline, mustard and other types of non-traditional vegetable oils).

The purpose of the study is to formulate a distribution model for oilseed processing products to promote and strengthen their competitive position in foreign markets, in the context of the development of the region's export activities.

As an object of study, we consider the products of the agricultural complex of the Krasnoyarsk Territory, in particular, oilseed processing products (an unconventional group of vegetable oils: cameline, mustard, rapeseed) mass production and sale of which is planned by the leading enterprises of the region [3].

\section{Materials and Methods}

\subsection{The results of a marketing study of the edible oils market}

Based on the studies of the state of the oil and fat industry [4, 5], market assessments of oilseeds and vegetable oils of China by the Russian Export Center, we consider it expedient to organize the production of oilseed processing in the Krasnoyarsk Territory. Without access to the outer foreign markets, new industries will not pay off, and the sale of large volumes of unconventional oils in the domestic market is an unrealistic task, given the prevailing consumption culture [6].

China's domestic consumption of vegetable oils has been steadily increasing in recent years. The potential of the Chinese market is huge.

According to the Russian Export Center (REC) [2], the most popular type of edible oil used in China is soybean oil (44\%), other edible oils (27\%), and rapeseed oil (11\%).

Rapeseed oil is of maximum popularity in Chengdu, Wuhan and Nanjing (Fig. 1). According to Euromonitor International, the dominant market position is held by the international holding Wilmar International, which accounts for about $40 \%$ of retail sales of edible oils. It is followed by the largest Chinese company on the market - COFCO, whose share in 2018 is $13.8 \%$.

According to the REC data [2], among the main channels for the distribution of edible vegetable oils in China in 2018 and over the past 5 years, multi-format stores predominate $96.5 \%$, so as the annual growth of online stores is also noted. 


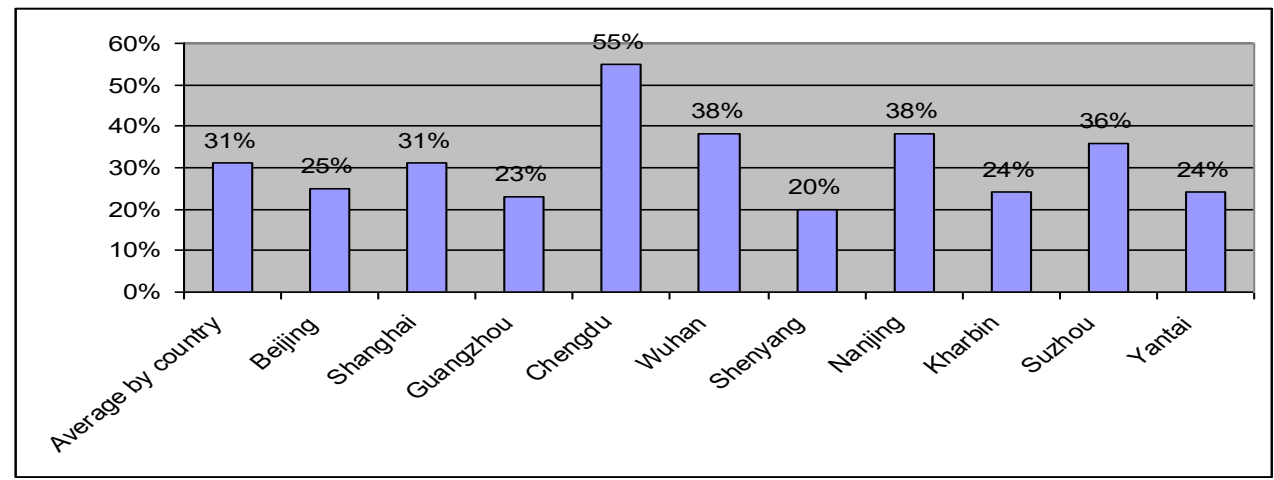

Fig. 1. Rapeseed oil purchases in Chinese cities, 2018. [Source: HKTDC]

Thanks to the correctly chosen strategy of gradual market development and differentiated marketing technologies, enterprises will be able to pave the way for interaction with consumers (Tables 1,2).

Table 1. The main criteria for segmenting consumers of vegetable oils

\begin{tabular}{|l|l|}
\hline \multicolumn{1}{|c|}{ Criteria } & \multicolumn{1}{c|}{ Key Characteristics } \\
\hline Geographical & in cities of China: Chengdu, Wuhan, Nanjing, Suzhou, Shanghai \\
\hline Demographic & men and women aged 20-60 \\
\hline Social & students, housewives working \\
\hline Economic & average income, above average income \\
\hline Behavioral & regularly cook at home,adherents of a healthy diet and quality products \\
\hline
\end{tabular}

Table 2. Elements of the marketing complex of the product group "Vegetable oils"

\begin{tabular}{|l|l|}
\hline \multicolumn{1}{|c|}{ Elements } & \multicolumn{1}{c|}{ Description } \\
\hline Product & $\begin{array}{l}\text { Rapeseed oil, in the future, camelina, mustard; Under the regional brand } \\
\text { "Oils of Siberia"; In bulk, bottled, Degree of purification: unrefined, Volume } \\
\text { 3, 5 liters; Compliance with quality indicators CIQ. }\end{array}$ \\
\hline Price & Average, pricing policy is based on the best balance of price-quality \\
\hline Physical distribution & $\begin{array}{l}\text { Supermarket and hypermarket chain "China Resources Vanguard", online } \\
\text { shopping: Tmall, JD, Suning, Pinduoduo, online shops. }\end{array}$ \\
\hline Promotion & $\begin{array}{l}\text { Advertising at points of sale, in specialized catalogs. Target products may be } \\
\text { presented as part of exhibition and fair events.: Food Expo Hong Kong, FHC } \\
\text { China Shanghai, ANUFOOD China; Hotelex, SIAL China Shanghai. }\end{array}$ \\
\hline
\end{tabular}

Let's consider the ways to deliver rapeseed oil produced in the Krasnoyarsk Territory to Chinese markets. Currently, the highest share of its consumption in the cities of Chengdu, Wuhan and Nanjing, i.e. territories adjacent to rapeseed cultivation areas. However, according to market research, food products produced in Russia are in great demand in China than the products of Chinese manufacturers and are perceived as of better quality. Therefore, when analyzing the transportation model, we will focus on the given cities.

\subsection{Delivery features and product distribution model}

Based on consumer segmentation and the formed marketing complex, it is justified to organize the delivery of oilseed processing products (vegetable oils) to Chengdu, Wuhan and Nanjing in large quantities by automobile transport. The use of rail transport seems inappropriate due to higher transport costs, as well as the lack of suitable container train routes to the given cities. 
Rapeseed oil, like other vegetable oils, is characterized by the properties of liquid bulk cargo (moreover, the potential consumers, according to research, are more interested in such supplies for the purpose of further packaging in China) [9]. Transportation can be carried out in two ways.

The first method is bulk. When carrying out international transportation, the container tank is believed to be optimal $[7,10]$.

The second way is packaged. In this case, the products are loaded into airtight containers (cans, bottles, barrels, etc.), transported mainly in a container way by means of euro pallets. Containers are transported in insulated vans, tilt trailers and semi-trailers. It is necessary to take into account the permitted number of tiers and apply methods of securing the cargo, excluding the drop and collision of the containers, as well as the maximum permissible time the cargo was on the way (1 month) $[7,9]$.

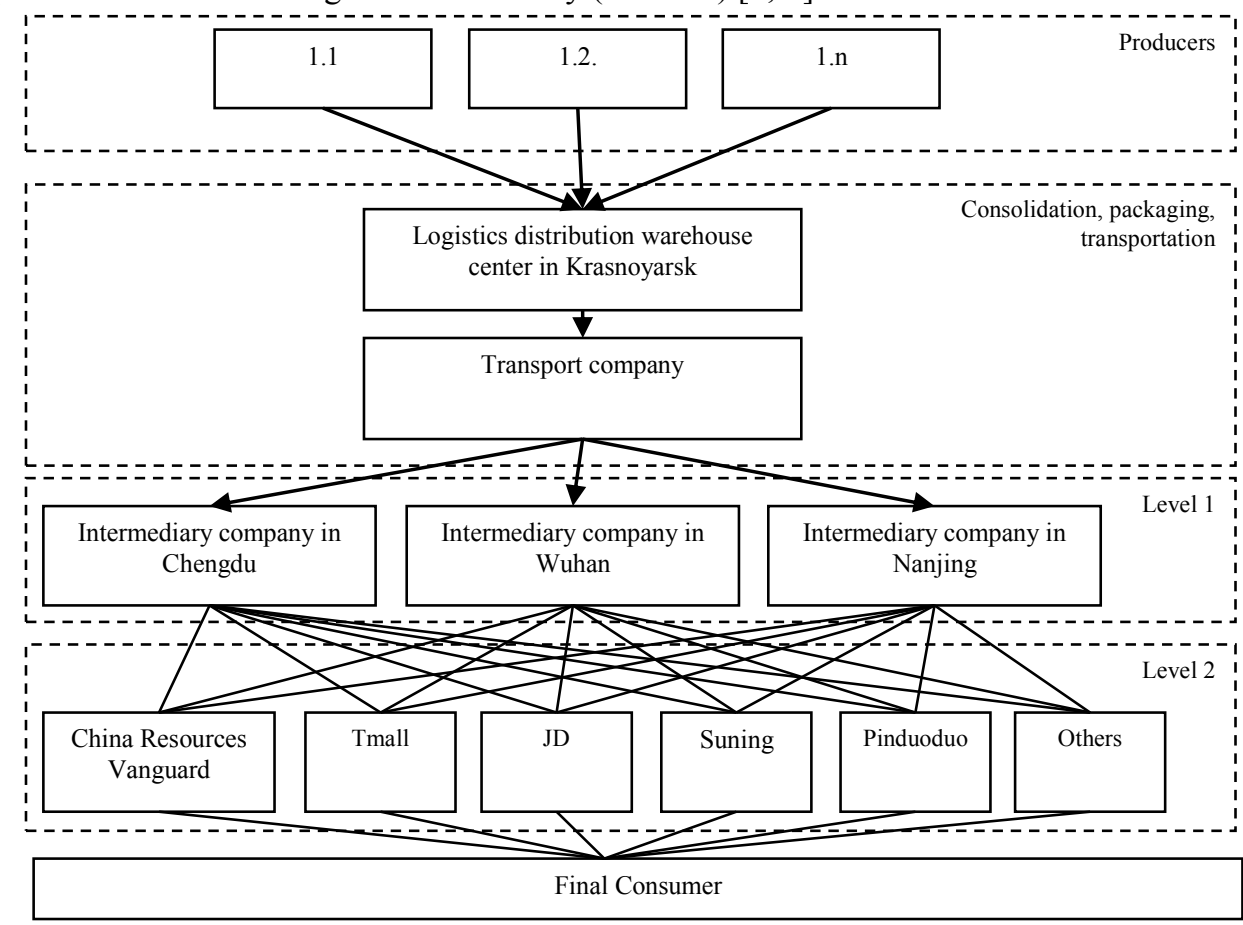

Fig. 2. The distribution model for oilseed processing products (vegetable oils). [Source: compiled by the authors]

At present, the use of flexitanks, which is described as a flexible container with a volume of up to 24,000 liters, installed into a standard 20-foot container [11], is considered to be the optimal way to deliver small and medium-sized batches of bulk cargo, including vegetable oils. Due to the standardization of the containerized method of cargo transportation, transportation by road, sea, and rail is also acceptable [7].

The proposed distribution model for oilseed processing products (vegetable oils) is presented in Figure 2. Within the logistics distribution warehouse center located in Krasnoyarsk, products are consolidated, packaged, and otherwise prepared for shipment. After that, the cargo is transferred to a transport company that delivers products to designated cities in China. 


\section{Results and Discussion}

We have to estimate the amount of transportation costs for the delivery of rapeseed oil to the cities of Chengdu, Wuhan and Nanjing.

As of the beginning of 2020, there are 24 border crossings between China and the Russian Federation [8]. However, the location of these crossings on the territory of the Far Eastern Federal District increases the length and cost of delivery. Cargo delivery through the territory of Mongolia seems to us impractical due to the additional costs of customs clearance and the low quality of the roadway in the republic. In addition, in some cases (delivery of goods to the central and western provinces of China), it is more expedient to transit cargo through the territory of the Republic of Kazakhstan (border station Dostyq), which is part of the Eurasian Customs Union.

Based on the analysis of the cost of freight in the Russian Federation, the cost of delivering rapeseed oil from the Krasnoyarsk Territory to Chinese cities will be 2.92 rubles. per 1 ton-kilometer, subject to the use of flexitank transportation method (Table 3).

Table 3. Bulk cost of rapeseed oil delivery

\begin{tabular}{|c|l|c|c|}
\hline City & \multicolumn{1}{|c|}{ Delivery route } & $\begin{array}{c}\text { Route length, } \\
\text { km. }\end{array}$ & $\begin{array}{c}\text { Delivery } \\
\text { cost, rubles }\end{array}$ \\
\hline Chengdu & $\begin{array}{l}\text { through the territory of Kazakhstan (Route } \\
\text { Krasnoyarsk - Kemerovo - Barnaul - Rubtsovsk - } \\
\text { Lokot' (boarder) - Semey - Ayagoz - Dostyq } \\
\text { (boarder) - Urumqi - Lanzhou - Chengdu) }\end{array}$ & 5500 & 342100 \\
\hline Wuhan & $\begin{array}{l}\text { bypassing the territory of Mongolia (Krasnoyarsk - } \\
\text { Tayshet - Irkutsk - Ulan-Ude - Chita - Zabaykalsk - } \\
\text { Manchuria - Beijing - Wuhan) }\end{array}$ & 6000 & 353320 \\
\hline Nanjing & $\begin{array}{l}\text { bypassing the territory of Mongolia (Krasnoyarsk - } \\
\text { Tayshet - Irkutsk - Ulan-Ude - Chita - Zabaykalsk - } \\
\text { Manchuria - Shenyang - Tianjin - Nanjing) }\end{array}$ & 5600 & 359744 \\
\hline
\end{tabular}

Also, we will determine the cost of transportation of bottled rapeseed oil (in containers of 5 liters) (Table 4). Since the maximum load in a 20 -foot container will be $13024 \mathrm{~kg}$ of bottled rapeseed oil, the cost of delivery of 1 consignment will be 4.24 rubles. for 1 tonkilometer. Accordingly, the cost of sending 1 consignment to Chengdu, Wuhan and Nanjing will be 211,992 rubles., 231,264 rubles., 215846 rubles. respectively (Table 4).

Table 4. Bottled Rapeseed Oil Delivery Cost

\begin{tabular}{|l|c|c|}
\hline \multicolumn{1}{|c|}{ Delivery Options } & $\begin{array}{c}\text { Unit of } \\
\text { measurement }\end{array}$ & Value \\
\hline dimensions of a 5 liter bottle & $\mathrm{mm}$ & $150 \times 128 \times 310$ \\
\hline 1 pallet & $\mathrm{mm}$ & $1200 \times 800$ \\
\hline at 1 pallet & boxes & 48 \\
\hline maximum loading capacity of 20 foot container & bottles & 2850 \\
\hline transportation fare & rubles & 192000 \\
\hline cost of packaging & rubles per one & 20 \\
\hline $\begin{array}{l}\text { customs clearance services and the provision of electronic digital } \\
\text { signature (EDS) of the Customs representative }\end{array}$ & rubles & 18000 \\
\hline $\begin{array}{l}\text { Registration at the temporary storage warehouse along the route, } \\
\text { including VAT }\end{array}$ & rubles & 30000 \\
\hline Total cost of 1 transportation: & rubles & 296400 \\
\hline
\end{tabular}

Rapeseed oil, being a final consumption product, needs the widest possible market coverage. The consequence of this is the need to form long distribution channels for 
products: delivering them to an intermediary company in the PR of China with further distribution of products to retail outlets by its forces. This will allow sending products in larger batches with savings on the transportation costs of the sender (storage costs in this case are imposed on the intermediary company).

\section{Conclusion}

To design the optimal distribution model, it is necessary firstly to assess the foreign market through marketing information on target markets. The decision to enter foreign markets should be balanced and informed, and in an ideal situation - based on an objective analysis. A comprehensive assessment of the strategic prospects of each channel, taking into account the market orientation of the enterprise, will allow us to design and optimize a distribution model based on the specifics of a particular product and the expectations of a particular market.

The formed distribution model is focused on the goals of the agricultural enterprises of the Krasnoyarsk Territory: to introduce a new product (vegetable oils: rapeseed, cameline, mustard) and expand its presence in foreign markets. In a strategic perspective, the model will expand the possibilities of diversifying the activities of agricultural enterprises in the region when entering foreign markets and will serve as a serious methodological basis for the design of innovative business models.

\section{Acknowledgements}

The project "Development of the formation and promotion model of the Krasnoyarsk territory regional brand in the category "processed products of oilseed crops"” was funded by Krasnoyarsk Regional Fund of Science.

\section{References}

1. Agriculture, portal territorial body of the federal state statistics service of the Krasnoyarsk territory. URL: https://krasstat.gks.ru/folder/44270

2. Analytics and research, export commodity report, portal Russian export center. URL: https://www.exportcenter.ru/services/analitika-i-issledovaniya/

3. N. Pyzhikova, K. Chepeleva, Zh. Shmeleva, Advances in Economics, Business and Management Research, 128, 2214-2225 (2019)

4. K. Chepeleva, Zh. Shmeleva, IOP Conference Series: Earth and Environmental Science, 421 (2020)

5. A. Kolomeytsev, N. Pyzhykova, K. Chepeleva, Science and business: development paths, 12, 288-292 (2019)

6. The Russian vegetable oil market continues to grow. Agrovestnik. URL: https://agrovesti.net/lib/industries/oilseeds/rossijskij-rynok-rastitelnogo-maslaprodolzhaet-rasti.html

7. Transportation of vegetable oil, portal interlogistica. URL: https:/mosinterlogistics.com/info/perevozka-rastitelnogo-masla/

8. The list of border crossings between Russia and China, portal regional center for innovative technologies. URL: http://www.rcit.su/inform-pprf-ppen.html

9. GOST R 52465-2005. Sunflower oil. Technical conditions. National Standard of the Russian Federation. URL: http://docs.cntd.ru/document/1200043577

10. Types and classification of tank-containers, portal transport industrial service. URL: https://www.oootis.com/tank-containers-varieties 
11. Flexitanks, portal flexitank.biz. URL: http://flexitank.biz/ru/products 